\title{
Mapping Biochemical Pathways in Maytenus ilicifolia (Celastraceae) through Integrated Proteomics and Histochemistry
}

\author{
Vânia A. F. F. M. Santos, ${ }^{\circledR a}$ Nathalia B. Dias, ${ }^{b}$ Simone P. Teixeira, ${ }^{c}$ Mario S. Palma ${ }^{d}$ and Maysa Furlan ${ }^{\circledR} * a$ \\ ${ }^{a}$ Instituto de Química, Universidade Estadual Paulista (Unesp), 14800-060 Araraquara-SP, Brazil \\ ${ }^{b}$ Scientific and Technological Bioresource Nucleus BIOREN-UFRO, \\ Universidad de La Frontera (UFRO), 4811-230 Teтисо, Chile
}

'Laboratório de Botânica, Faculdade de Ciências Farmacêuticas de Ribeirão Preto, Universidade de São Paulo (USP), 14040-903 Ribeirão Preto-SP, Brazil

${ }^{d}$ Departamento de Biologia Geral e Aplicada, Instituto de Biociências, Universidade Estadual Paulista (Unesp), 13506-900 Rio Claro-SP, Brazil

\begin{abstract}
Maytenus ilicifolia (Celastraceae) is a medicinal plant that is native to southern Brazil and is popularly known as "espinheira-santa". From a biosynthesis perspective, this species accumulates quinonemethide triterpenes and sesquiterpene pyridine alkaloids as major secondary metabolites that exhibit interesting biological properties, with antitumoral and antiprotozoal activities, respectively, being the most frequently reported. Additionally, the restricted accumulation of such compounds in the roots raises questions about the expression of proteins involved in such compartmentalization and their possible biological and/or ecological role in M. ilicifolia. Thus, this article describes the use of shotgun proteomics and histochemical studies for the characterization of the main biosynthetic pathways involved in the regulation of the metabolism in M. ilicifolia roots. This combined approaches also resulted in the identification of a series of proteins involved in the quinonemethide triterpenes and sesquiterpene pyridine alkaloids, providing evidences of their differential compartmentalization.
\end{abstract}

Keywords: shotgun proteomic approach, histochemical analysis, quinonemethide triterpenes, sesquiterpene pyridine alkaloids, Maytenus ilicifolia, Celastraceae

\section{Introduction}

Plant growth and development are regulated by phytohormones and mediate responses to biotic and abiotic stresses. ${ }^{1}$ In response to stress, plants synthesize and accumulate a wide diversity of secondary metabolites, which are involved in biological and ecological functions. ${ }^{2,3}$

Many of these compounds have shown biological activity and are considered to be prototypes for the synthesis of a large number of drugs, ${ }^{4}$ accounting for more than $50 \%$ of all drugs employed in modern therapies. ${ }^{5}$

The biosynthesis of these metabolites is performed by specific pathways and involves complex interactions between proteins/enzymes, transport mechanisms, compartmentalization, and integration with primary metabolism at the molecular and cellular levels. ${ }^{3,6}$

Maytenus ilicifolia Mart ex Reissek is a medicinal

*e-mail: maysa.furlan@unesp.br plant native to southern Brazil that is popularly known as "espinheira-santa". Since 1988, this plant has been included as herbal medicine in the phytotherapy program, coordinated by the Brazilian Ministry of Health's Medicines Center (CEME), and was included in the National List of Medicinal Plants of Interest for the Brazilian Unified Health System (SUS). ${ }^{7}$

The structural richness of Maytenus ilicifolia roots is exemplified by quinonemethide triterpenes and sesquiterpene pyridine alkaloids (Figure 1), which are considered chemotaxonomic markers of the Celastraceae species. ${ }^{8}$ Several biological activities have been described for these two classes of metabolites, including antioxidant, antifungal, antiproliferative, antiprotozoal, antitumoral, antimicrobial, and inhibitor of hepatitis $\mathrm{C}$ virus, antiprotozoal, relating to quinonemethide triterpenes and sesquiterpene pyridine alkaloids, respectively. ${ }^{9-19}$

Thus, this study aimed to (i) localize the metabolites through histochemical tests, (ii) characterize the main proteins involved in primary and secondary metabolism 


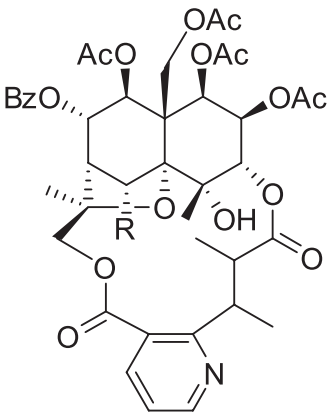

$\mathbf{R}$

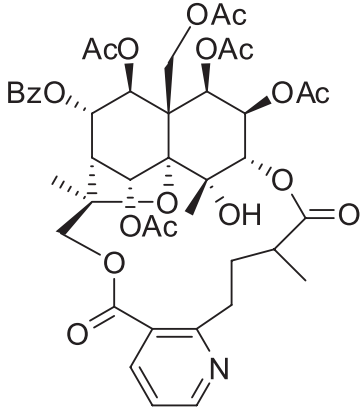

2

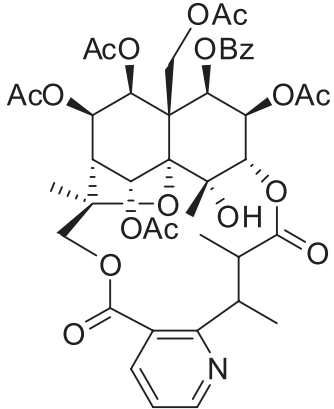

4

$1 \mathrm{OH}$

3 OAc

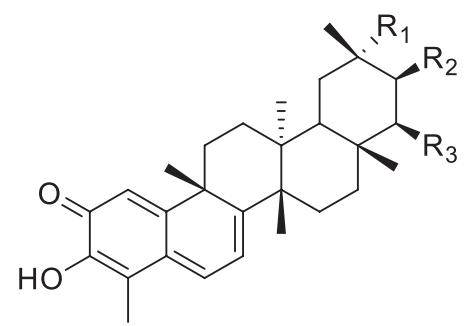

$\begin{array}{llll} & \mathbf{R}_{\mathbf{1}} & \mathbf{R}_{\mathbf{2}} & \mathbf{R}_{\mathbf{3}} \\ \mathbf{5} & \mathrm{CO}_{2} \mathrm{CH}_{3} & \mathrm{H} & \mathrm{H} \\ \mathbf{6} & \mathrm{H} & \mathrm{O} \text { (keto) } & \mathrm{H} \\ 7 & \mathrm{H} & \text { O (keto) } & \mathrm{OH}\end{array}$

Figure 1. Chemical structures of sesquiterpene pyridine alkaloids: ilicifoliunine A (1), ilicifoliunine B (2), aquifoliunine E-I (3) mayteine (4) and quinonemethide triterpenes: pristimerin (5), maytenin (6), 22ß-hydroxy-maytenin (7), isolated from Maytenus ilicifolia.

by means of proteomic studies, and (iii) combine the histochemical and proteomic data. These approaches aimed to identify the main biosynthetic pathways active in M. ilicifolia roots, determine and provide evidence of a differential distribution of the metabolites and to address the possible biological and ecological functions that these compounds serve in the roots of M. ilicifolia.

\section{Experimental}

\section{Plant material}

Young plants (five years old) of Maytenus ilicifolia ware collected in the district of Juruce, municipality of Jardinópolis, state of São Paulo (21 ${ }^{\circ} 04$ '18.8"'S; $47^{\circ} 44^{\prime} 08.8^{\prime \prime} \mathrm{W}$ ) in March 2013. After collection, the plants were transported and maintained in a greenhouse at the Instituto de Química de Araraquara, state of São Paulo (2148'26.62"S; 48¹1'33.5”W).

The botanical identification was provided by Prof Rita Maria de Carvalho-Okano. A voucher specimen (00755) was deposited in the Herbarium of the Department of Medicinal Plants, University of Ribeirão Preto, São Paulo, Brazil (HPM-UNAERP).

\section{Histological analysis}

For the histochemical tests, lateral roots were selected. Cross-sections were made manually and transferred to a watch glass containing deionized water. Later, these cross-sections were selected using a magnifying glass to obtain the thinnest cuts and cuts with correct orientation. After the selection of the cuts, some of them were kept unstained to verify the natural appearance of the cellular content, and the other part was submitted to different reagents, aiming to achieve in situ detection of different classes of metabolites. The following reagents were used for the histochemical tests: Sudan III (Sigma-Aldrich, St. Louis, USA) for lipophilic compounds (lipids, terpenoids, suberin and cutin), ferric chloride (Fisher Scientific, Waltham, USA) for phenolic compounds, and Dragendorff reagents for alkaloids..$^{20,21}$ The cuts were then mounted between a slide of glass and coverslip and analyzed under a microscope. The observations and photomicrographs were obtained from a Leica DFC 320 digital camera coupled to a Leica (Wetzlar, Germany) DM 5000 microscope. Autofluorescence was monitored by an epifluorescence microscope equipped with a mercury lamp and green light (excitation, $488 \mathrm{~nm}$; emission longpass filter, $520 \mathrm{~nm}$ ).

\section{Proteomic analysis}

\section{Protein extraction}

The total proteins were extracted and precipitated according to the methodology developed by Hurkman and Tanaka ${ }^{22}$ with some modifications. Approximately $7 \mathrm{~g}$ of the roots were ground to form a thin paste. Subsequently, the material was transferred to centrifuge tubes containing $60 \mathrm{~mL}$ of 
extraction buffer containing this buffer: $0.7 \mathrm{M}$ sucrose, 0.1 $\mathrm{M} \mathrm{KCl}, 0.5 \mathrm{M}$ Tris-HCl pH 7.5, $1 \mathrm{mM}$ phenylmethylsulfonyl fluoride (PMSF) dissolved in isopropanol, $50 \mathrm{mM}$ ethylenediaminetetraacetic acid (EDTA) and 1\% (m/v) polyvinylpolypyrrolidone (PVPP) (Sigma-Aldrich, St. Louis, USA). The mixture was homogenized at $4{ }^{\circ} \mathrm{C}$ for $30 \mathrm{~min}$ on an orbital shaker.

Then, the same volume of phenol equilibrated with a solution of $10 \mathrm{mM}$ Tris-HCl (Sigma-Aldrich, Saint Louis, USA) pH $7.9 \pm 0.2$ and 1 mM EDTA (Sigma-Aldrich, St. Louis, USA) was added. The mixture was further stirred for $30 \mathrm{~min}$ and finally centrifuged at $4{ }^{\circ} \mathrm{C}$ and $10000 \times \mathrm{g}$ for $30 \mathrm{~min}$. Then, the supernatant (upper phase or phenolic) was transferred to a new tube, and 1 volume of extraction buffer with $0.15 \mathrm{~g}$ of PVPP was added. The samples were homogenized in the same manner with the aid of an orbital shaker for $30 \mathrm{~min}$ at $4{ }^{\circ} \mathrm{C}$. Subsequently, the samples were subjected to centrifugation at $4^{\circ} \mathrm{C}$ and $10000 \times \mathrm{g}$ for $30 \mathrm{~min}$. The upper phase was again collected and added (1 volume) extraction buffer but without the addition of PVPP. Again, the upper phase was homogenized and centrifuged. The supernatant was recovered, and 5-6 volumes $(25-30 \mathrm{~mL})$ of precipitation buffer $(100 \%$ methanol $+0.1 \mathrm{M}$ ammonium acetate) was added, and samples were kept frozen at $-20^{\circ} \mathrm{C}$ overnight. After this time, the samples were centrifuged at $7000 \times \mathrm{g}$ for $40 \mathrm{~min}$ at $4{ }^{\circ} \mathrm{C}$, and the supernatant was discarded. Then, proteins were washed with the addition of 5-6 volumes of ice-cold methanol and then washed with cold acetone $\left(-20^{\circ} \mathrm{C}\right)$. The process of washing and centrifugation of the proteins was repeated two times. In each step, proteins were washed and left for $1 \mathrm{~h}$ at $-20^{\circ} \mathrm{C}$ and centrifuged at $7000 \times \mathrm{g}$ for $40 \mathrm{~min}$ at $4{ }^{\circ} \mathrm{C}$. The protein pellets were dried at $4{ }^{\circ} \mathrm{C}$ in a desiccator connected to a vacuum pump. The protein concentration was determined as described by Bradford using a protein assay kit Bio-Rad (Hercules, CA, USA) and bovine serum albumin (BSA) (Sigma-Aldrich, St. Louis, USA) as a standard. Exudate protein samples were stored at $-80{ }^{\circ} \mathrm{C} .{ }^{23}$

\section{Tryptic in-solution digestion}

Proteins were solubilized in $50 \mu \mathrm{L}$ ammonium bicarbonate $\left(\mathrm{NH}_{4} \mathrm{HCO}_{3}\right.$, Sigma-Aldrich, St. Louis, USA) $50 \mathrm{mM}, \mathrm{pH} 7.9$, containing 7.5 M urea (Sigma-Aldrich, St. Louis, USA) for $1 \mathrm{~h}$ at $37{ }^{\circ} \mathrm{C}$ and then reduced with $10 \mathrm{mM}$ dithiothreitol (DTT) (Sigma-Aldrich, St. Louis, USA) at $37^{\circ} \mathrm{C}$ for $1 \mathrm{~h}$. After this treatment, the proteins were alkylated with $40 \mathrm{mM}$ iodoacetamide (IAA) at $25^{\circ} \mathrm{C}$ for $1 \mathrm{~h}$ in the dark. Subsequently, the samples were diluted five times with ammonium bicarbonate $100 \mathrm{mM}, \mathrm{pH} 7.8$, and calcium chloride at a concentration of $1 \mathrm{mM}$. Trypsin (Promega, Madison, WI, USA) was added to the denatured protein solution $\left(1: 50 \mathrm{~m} / \mathrm{m}\right.$ trypsin:protein) for $18 \mathrm{~h}$ at $37{ }^{\circ} \mathrm{C}$. The reaction was terminated with the addition of $5 \mu \mathrm{L}$ formic acid.

The digested samples were desalted using a Sep-Pak tC18 $1 \mathrm{~cm}^{3}$ Vac Cartridge (Waters, Milford, MA, USA) column. The tryptic peptides were solubilized in $50 \%$ acetonitrile (ACN) and subjected to analysis in a liquid chromatography coupled with time-of-flight and ion trap mass spectrometry (LCMS-IT-TOF) and MS ${ }^{\mathrm{n}}$ system.

\section{LCMS-IT-TOF}

The samples were analyzed using the LCMS-IT-TOF system. The UFLC (ultra fast liquid chromatograph) system (Shimadzu, Kyoto, Japan) coupled directly (online) to the mass spectrometer, with two LC-20AD pumps, an SPD-M20A diode array detector, a SIL-20AHT autosampler and a CTO-20A oven column was used. The analysis was carried out under a gradient of acetonitrile (ACN) from 5 to $90 \%(\mathrm{v} / \mathrm{v})$ containing $0.05 \%$ trifluoroacetic acid (TFA) (v/v) over 90 min using a C18 Shim-pack XR-ODS column $(3 \times 100 \mathrm{~mm}, 120 \mathrm{~A}, 2.2 \mu \mathrm{m})$ (Shimadzu). The elution of components was monitored by ultraviolet absorbance at $214 \mathrm{~nm}$ through a UFLC system with a flow rate of $0.2 \mathrm{~mL} \mathrm{~min} \mathrm{~min}^{-1}$ for $90 \mathrm{~min}$. The eluents were analyzed in continuous positive mode $\left(\mathrm{ESI}^{+}\right)$throughout the experiment.

The mass spectra were obtained on a mass spectrometer with an ESI source, the type "ion trap-time of flight" (IT-TOF Shimadzu). LCMS solution (Shimadzu) was used to control the acquisition and data analysis. During all experiments, the temperature of the curved desolvation line (CDL) and the interface was maintained at $200{ }^{\circ} \mathrm{C}$, the voltage on the needle was maintained at $4.5 \mathrm{kV}$, and the cone voltage was maintained at $3.5 \mathrm{~V}$. The flow of drying gas (nitrogen) was $100 \mathrm{~L} \mathrm{~h}^{-1}$, and the nebulizer gas flow (nitrogen) was $1.5 \mathrm{~L} \mathrm{~h}^{-1}$. The detection in the mass spectrometer was made to scan in the range $m / z, 200-4000$ with a resolution of approximately 15000 , and the data acquisition system was continuously operated in positive mode.

The sequential mass spectrometry or fragmented peptide $\left(\mathrm{MS}^{2}\right)$ experiments were carried out using the same parameters as the MS experiments. Argon was used as the collision gas at a pressure of $100 \mathrm{kPa}$. The ions produced by the $\mathrm{MS}^{2}$ (and $\mathrm{MS}^{3}$ ) experiments were imprisoned and retained for $50 \mathrm{~ms}$ in ion trap using a collision energy of $50 \%$ and frequency of $30 \mathrm{kHz}$.

The mass spectra obtained were first analyzed with the tools of LCMS Solution (Shimadzu) software to control data acquisition and analysis.

\section{Protein identification}

The MS and $\mathrm{MS}^{\mathrm{n}}$ data were combined to search with a taxonomic restriction of Viridiplantae (Green Plants) 
against the National Center for Biotechnology Information nonredundant protein database (NCBInr) ${ }^{24}$ and Swiss-Prot ${ }^{25}$ protein database using the Mascot algorithm 2.2.06 (Matrix Science, London, UK). ${ }^{26}$

The parameters used to search the databases were a mass tolerance of $0.5 \mathrm{Da}$ and a peptide mass tolerance of 0.8 Da peptide fragments, and the number of missing cleavages was set to 1 . Modifications of the peptides were considered: carbamidomethyl (C) and oxidation of methionine and tryptophan. The values of "ion score" and "protein score" were considered significant values preset by the bioinformatic tool used. The FDR (false discovery rate) was calculated using the original decoy FDR approach from Mascot, provided by Matrix Science. ${ }^{26}$ The FDR thresholds for protein and peptides were selected between 0.1 and 0.01 and ion score values were set to $>19$. FDR was calculated based on the Mascot Score. ${ }^{26}$ Proteins were accepted if they were confidently identified at $\geq 99.0 \%$ probability as assigned by the Protein Prophet algorithm incorporated in the software.

\section{Functional and gene ontology (GO) analysis}

The proteins identified by $\mathrm{Mascot}^{26}$ were further annotated with Gene Ontology (GO) terms according to UniProt Knowledgebase (UniProtKB) ${ }^{27}$ and mapped against the GO database by using the Blast2GO software. ${ }^{28,29}$ Additionally, the proteins with Enzyme Commission (EC) numbers obtained from the Blast2GO software were mapped onto the Kyoto Encyclopedia of Genes and Genomes (KEGG) Pathway Database. ${ }^{30}$ A complete list of all identified proteins is provided in the Supplementary Information (SI) section.

\section{Results and Discussion}

\section{Histochemical analysis}

The analysis of the anatomical sections showed roots in secondary structure, with secondary xylem, secondary phloem, remains of a cortex and periderm (phellem, phellogen and phelloderm), in which a large number of cells containing starch grains was observed (Figures 2a-2b).

The quinonemethide triterpenes were predominantly evidenced on phellem cells when cross-sections of the roots were subjected to reagent Sudan III (Figure 2c). The quinonemethide triterpenes also showed compartmentalization on cortex cells and secondary xylem cells (Figure S1, SI section). In addition, the suberin shows orange coloration when submitted to treatment with Sudan III (Figure 2c).
Additionally, the histochemical analysis enabled us to locate the quinonemethide triterpenes in the outermost layers that make up the periderm (phellem, phellogen and phelloderm), more precisely the phellem, which is characterized by having its cell walls suberized (Figure 2c). These results are consistent with a recent report, ${ }^{31}$ which showed that celastrol and demethylzeylasteral, two quinonemethide-type triterpenes, accumulate in suberized cell walls.

The presence of alkaloids was confirmed by treatment of the sections with Dragendorff reagent. These alkaloids were observed in the phellem cells and in the cortex cells and fibers of secondary xylem stored in the cytoplasm, showing a granular appearance (Figures 2e-2f), corroborating a previous work. ${ }^{31}$

Phenolic compounds were observed in the cortical cells after staining with ferric chloride (Figure 2d). The detection of autofluorescence was monitored by epifluorescence microscopy, corroborating the accumulation of terpenes in the phellem cells and the phenolic compounds in the walls of some cells of the cortex and secondary xylem (Figures 2g-2h).

The presence of terpenes, alkaloids and phenolic compounds in the roots of $M$. ilicifolia is not associated with specialized structures in the secretion (processes of production and release) of secondary metabolites, such as secretory structures, but rather with cells nonspecialized in secretion.

Histochemical tests indicated that the root cells contain a diversity of metabolites, including terpenes, alkaloids, flavonoids and starch. This analysis obtained novel results for M. ilicifolia and strongly corroborated the chemical, ${ }^{9}$ biological, ${ }^{11-13}$ biosynthetic ${ }^{32}$ and proteomic studies.

\section{Proteomic analysis}

The shotgun proteomic analysis of the soluble fractions of roots from $M$. ilicifolia led to the identification of 436 proteins using the Mascot algorithm against the NCBInr and Swiss-Prot databases, of which 83 proteins were common to both databases. After the identification of 364 proteins, from the total of 436 proteins (UniProt database), they were submitted to the Blast2GO bioinformatics tool, of which 351 proteins were mapped and annotated (Table S1, SI section).

All of the identified proteins were categorized according to biological process, cellular component and molecular function at the third level (Figure 3).

According to the biological process categorization (Table S2, SI section), the groups with the highest number of proteins identified are related to organic metabolism 

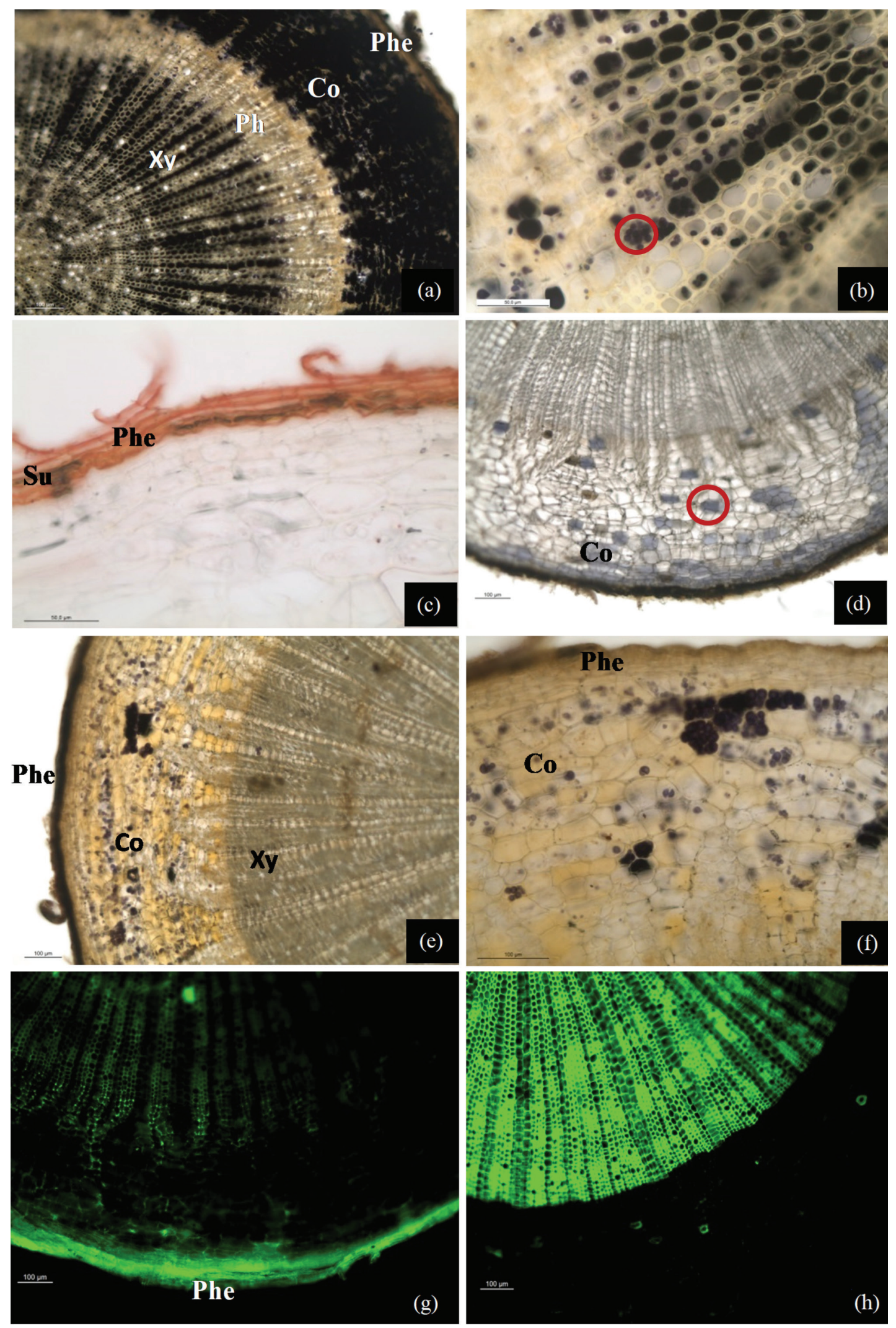

Figure 2. Photomicrographs of cross-sections of the root in secondary structure of M. ilicifolia. (a) Presence of starch grains (in black) in the secondary xylem (Xy), secondary phloem (Ph), cortex (Co), and phellem (Phe). (b) Featured (in black) starch grains in the fibers of secondary xylem. (c) Presence of terpenes (in orange-red) and suberin (in orange) in the phellem cells (Phe). (d) Presence of phenolic compounds (bluish black) in the cortical parenchymatic cells (Co). (e, f) Presence of alkaloids (dark brown) in phellem cells (Phe), cortical parenchymatic cells (Co), and secondary xylematic cells (Xy). Epifluorescence: (g) terpenes located in the phellem cells and (h) lignin in the cell walls of cortex and secondary xylem. Bars $=100 \mu \mathrm{m}(\mathrm{a}, \mathrm{d}, \mathrm{e}, \mathrm{f}$ and $\mathrm{g})$ and $50 \mu \mathrm{m}(\mathrm{b}$ and $\mathrm{c})$. 
process (299), primary metabolic process (286), cellular metabolic process (259) and single-organism metabolic process (228) followed by biosynthetic process (173), single-organism cellular process (123), nitrogen compound metabolic process (114), response to stress (99) and catabolic process (65) (Figure 3a).

Regarding the categorization of cellular components, intracellular (286), intracellular part (280), and intracellular organelles (222) were found followed by membranebound organelles (196), cell peripheries (68), plasma

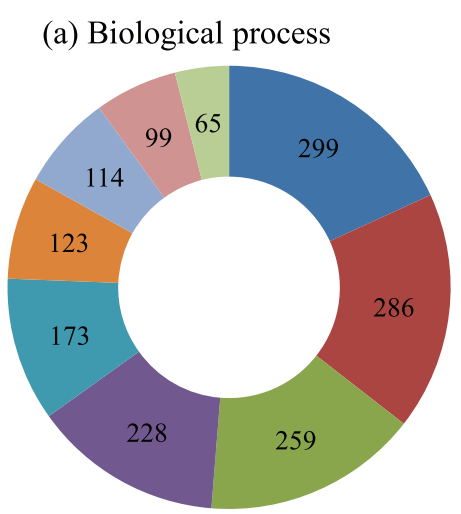

(b) Cellular components

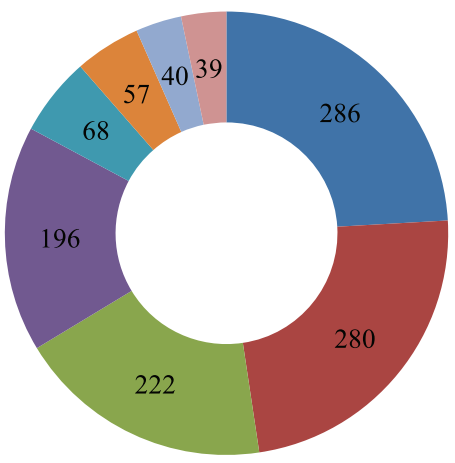

(c) Molecular functions

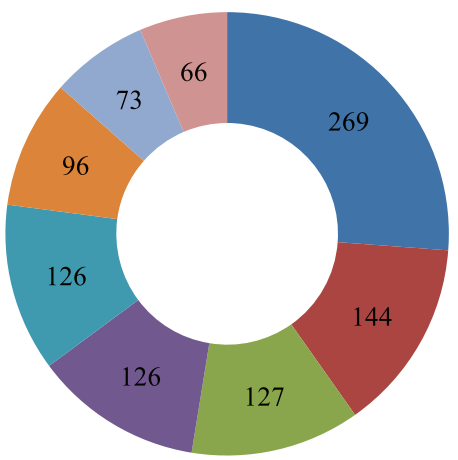

membranes (57), nonmembrane-bound organelles (40) and protein complexes (39) (Figure 3b). The main bonds and activities observed to molecular functions are related to ion binding (269), transferase activity (144), oxidoreductase activity (127), organic cyclic compound binding (126), heterocyclic compound binding (126), hydrolase activity (96), protein binding (73) and small molecule binding (66) (Figure 3c).

As this work aims to integrate histochemical and proteomic data to characterize the compartmentalization

- organic substance metabolic process

- primary metabolic process

- cellular metabolic process

- single-organism metabolic process

biosynthetic process

single-organism cellular process

nitrogen compound metabolic process

response to stress

catabolic process

n intracellular

— intracellular part

- intracellular organelle

membrane-bounded organelle

ncell periphery

- plasma membrane

non-membrane-bounded organelle

protein complex

घion binding

- transferase activity

n oxidoreductase activity

- organic cyclic compound binding

neterocyclic compound binding

hydrolase activity

protein binding

- small molecule binding

Figure 3. Functional category distribution of the identified proteins from M. ilicifolia. The functional annotation of the proteins was based on gene ontology (GO). Proteins were annotated according to biological processes (a), cellular components (b) and molecular functions (c) at the third level, using the Blast2GO tool. The distribution of the proteins in each category is indicated in the sectors of the circle. 
and expression of proteins related to primary and secondary metabolism, the category "biological process" and the subcategories biosynthetic process/response to stress were analyzed (Table S2, SI section). The proteins identified in the subcategory biosynthetic process consist of proteins related to the biosynthesis of phytohormones and secondary metabolites.

Proteins involved in the biosynthetic process and response to stress

The shotgun proteomic analyses led to the identification of important proteins involved in the biosynthetic pathway of phytohormone auxin, including anthranilate synthase and indole-3-pyruvate monooxygenase (Table 1). This phytohormone is involved in many aspects of plant growth and development, including controlling root development. ${ }^{33}$

Important proteins involved in the biosynthesis of jasmonic acid, such as lipoxygenase and allene oxide synthase, were also identified (Table 1). Oxylipins originate from $\alpha$-linolenic acid (EC number and KEGG map, Table S3 and Figure S2, SI section), many of which act as an important class of signaling molecules in defense responses to pathogens, insect herbivory and abiotic stresses..$^{34}$ In our study, we identified many proteins related to pathogenesis, such as nucleotide binding leucine-rich repeat (NB-LRR), pathogenesis related (PR) (osmotin, defensin, peroxidase, chitinase), thaumatin-like, and callose synthase.

It was also possible to show the occurrence of enzymes involved in the biosynthesis of phytohormones, cytokinin, abscisic acid, gibberellins and strigolactone (Table 1). These proteins interact either synergistically or antagonistically with auxin to trigger cascades of events leading to root morphogenesis and development. ${ }^{35}$

A large number of receptor kinases play an important role in a variety of biological processes, including growth, development, involvement in the phytohormone signaling pathway, and plant-microbe interactions. ${ }^{36}$

This analysis allowed us to identify many antioxidant enzymes that protect the cells and subcellular compartments of the plant from reactive oxygen species (ROS) effects, such as peroxidases and superoxide dismutase. ROS interact with phytohormones and are involved in growth and development processes and plant defense responses. ${ }^{37}$

The proteomic analysis culminated in the identification of several proteins that are located at a point of branching between the primary and secondary metabolisms, as well as in processes/mechanisms of defense of the plant against biotic and abiotic stresses. A number of enzymes related to the biosynthesis of phenylpropanoids were found (EC number and KEGG map, Table S3 and Figure S3, SI section), including phenylalanine ammonia-lyase (PAL), flavone 3'-O-methyltransferase and cinnamyl alcohol dehydrogenase (Table 1). Phenylpropanoids, such as flavonoids, anthocyanins, phytoalexins, plant hormones and lignins, play important roles in plant growth, development and pathology. ${ }^{38}$

Also, this analysis was enabled to identify enzymes involved in the mevalonate pathway, including isopentenyl pyrophosphate (IPP) and 3-hydroxy-3-methylglutarylcoenzyme A reductase (HMG-CoA). Important enzymes, such as $R$-linalool synthase and (+)-alpha-pinene synthase (Table 1), were also described. The systemic emission of these volatiles in the root could play a key role in the attraction of nematodes in the rhizosphere under attack by herbivores. ${ }^{39}$

The enzymes 3-hydroxy-3-methylglutaryl-coenzyme A reductase (HMG-CoA) and farnesyl diphosphate synthase (FPP) can be involved in the formation of the sesquiterpene unit of the dihydro- $\beta$-agarofuran of the sesquiterpene pyridine alkaloids (1-4, Figure 1) via the mevalonate pathway (MVA). These enzymes are also essential in the biosynthesis of triterpenoids and must be directly involved in the biosynthetic steps of 2,3-oxidoesqualene, a precursor of the quinonemethide triterpenes accumulated in M. ilicifolia. ${ }^{40-42}$

In addition, important enzymes are involved in the cyclization of 2,3-oxidosqualene (oxidosqualene cyclases (OSCs)), including lupeol and cycloartenol synthases, leading to the formation of lupeol and cycloartenol. Cycloartenol is a fundamental precursor in the biosynthesis of the phytohormone brassinosteroid, which plays diverse roles in plant growth and development. ${ }^{43}$ Triterpenes and steroids are oxidized by one or more cytochrome P450-type oxidoreductase enzymes. In our study, we identified cytochrome P450 85A, which is involved in the C6-oxidation step in brassinosteroid biosynthesis pathways (Table 1).

Additionally, proteomic analyses led to the identification of several enzymes involved in carbohydrate metabolic pathways. Interestingly, the alkaline/neutral invertase CINV2, which can cleave sucrose into glucose and fructose, has been suggested to be a target for signaling pathways that coordinate carbohydrate availability in growth and development in nonphotosynthetic organs. ${ }^{44}$

It was also possible to identify the occurrence of proteins that promote relaxation and cell wall extension in plants, such as expansins. These proteins play important roles in almost every phase of plant growth and confer tolerance in response to biotic and abiotic stresses. ${ }^{45}$

In addition, important proteins that make up the plant cytoskeleton, including actin and tubulin, were also identified. Cytoskeletal proteins are involved in many 
Table 1. Some proteins involved in biosynthetic processes identified in the root of $M$. ilicifolia using shotgun proteomic analysis

\begin{tabular}{|c|c|c|}
\hline $\begin{array}{l}\text { Accession } \\
\text { number }\end{array}$ & Protein & Biological process \\
\hline P29976 & phospho-2-dehydro-3-deoxyheptonate aldolase 1 & $\begin{array}{l}\text { chorismate biosynthetic process, aromatic amino acid family } \\
\text { biosynthetic process }\end{array}$ \\
\hline P42738 & chorismate mutase 1 , chloroplastic & $\begin{array}{l}\text { chorismate metabolic process, aromatic amino acid family } \\
\text { biosynthetic process }\end{array}$ \\
\hline I3ZNU8 & anthranilate synthase alpha-subunit 1 & tryptophan biosynthetic process \\
\hline G7J5E0 & anthranilate phosphoribosyltransferase & tryptophan biosynthetic process \\
\hline Q8VZ59 & indole-3-pyruvate monooxygenase YUCCA6 & auxin biosynthetic process \\
\hline Q7XH05 & probable aldehyde oxidase 1 & auxin biosynthetic process, abscisic acid biosynthetic process \\
\hline Q852M1 & probable aldehyde oxidase 2 & auxin biosynthetic process, abscisic acid biosynthetic process \\
\hline Q7G9P4 & abscisic-aldehyde oxidase & auxin biosynthetic process, abscisic acid biosynthetic process \\
\hline Q9C5X8 & molybdenum cofactor sulfurase & abscisic acid biosynthetic process \\
\hline P27481 & linoleate $9 S$-lipoxygenase & oxylipin biosynthetic process \\
\hline P93184 & lipoxygenase 2.1 , chloroplastic & oxylipin biosynthetic process \\
\hline Q9LNR3 & lipoxygenase 3 , chloroplastic & oxylipin biosynthetic process \\
\hline Q9FNX8 & lipoxygenase 4 , chloroplastic & oxylipin biosynthetic process \\
\hline Q8H016 & probable lipoxygenase 6 & oxylipin biosynthetic process \\
\hline Q69TI2 & putative 12-oxophytodienoate reductase 6 & oxylipin biosynthesis process \\
\hline P09918 & seed linoleate $9 S$-lipoxygenase-3 & oxylipin biosynthesis process \\
\hline Q7Y0C8 & allene oxide synthase 1 , chloroplastic & jasmonic acid biosynthetic process, oxylipin biosynthetic process \\
\hline Q93ZC5 & allene oxide cyclase 4 , chloroplastic & jasmonic acid biosynthetic process \\
\hline Q9SB60 & adenylate isopentenyltransferase 4 & cytokinin biosynthetic process \\
\hline Q5BPS0 & cytokinin riboside 5'-monophosphate phosphoribohydrolase LOG2 & cytokinin biosynthetic process \\
\hline Q43578 & lycopene beta cyclase, chloroplastic & carotenoid biosynthetic process \\
\hline Q40424 & lycopene beta cyclase, chloroplastic/chromoplastic & carotenoid biosynthetic process \\
\hline Q8VY26 & carotenoid cleavage dioxygenase 8 , chloroplastic & strigolactone biosynthetic process \\
\hline M1PK29 & 3-hydroxy-3-methylglutaryl-coenzyme A reductase 3 & isoprenoid biosynthetic process, coenzyme A metabolic process \\
\hline Q7XYS9 & farnesyl diphosphate synthase 1 & $\begin{array}{l}\text { farnesyl diphosphate biosynthetic process, geranyl diphosphate } \\
\text { biosynthetic process }\end{array}$ \\
\hline Q84KL6 & (-)-alpha-pinene synthase, chloroplastic & $\begin{array}{l}\text { alpha-pinene biosynthetic process, geranyl diphosphate metabolic } \\
\text { process }\end{array}$ \\
\hline A7IZZ2 & (+)-alpha-pinene synthase & alpha-pinene biosynthetic process \\
\hline Q9SPN0 & $R$-linalool synthase QH1, chloroplastic & terpenoid biosynthetic process, geranyl diphosphate metabolic process \\
\hline G5CV46 & viridiflorene synthase & terpenoid biosynthetic process \\
\hline F1CKJ1 & (+)-sabinene synthase, chloroplastic & metabolic process, terpene synthase activity \\
\hline Q8SA63 & beta-caryophyllene synthase & terpene synthase activity \\
\hline O82139 & cycloartenol synthase & pentacyclic triterpenoid biosynthetic process \\
\hline O82330 & cytosolic sulfotransferase 10 & brassinosteroid metabolic process, response to cytokinin \\
\hline Q69F95 & cytochrome $\mathrm{P} 45085 \mathrm{~A}$ & $\begin{array}{l}\text { oxidoreductase, catalyzes the C6-oxidation step in brassinosteroids } \\
\text { biosynthesis }\end{array}$ \\
\hline A8CDT3 & lupeol synthase & triterpenoid biosynthetic process \\
\hline Q9FZI2 & lupeol synthase 5 & $\begin{array}{l}\text { multifunctional enzyme that converts oxidosqualene to tirucalla-7,21- } \\
\text { diene-3beta-ol and two other triterpene monoalcohols }\end{array}$ \\
\hline Q9LS68 & putative pentacyclic triterpene synthase 7 & triterpene synthase \\
\hline Q42858 & phenylalanine ammonia-lyase & cinnamic acid biosynthetic process, phenylpropanoid metabolism \\
\hline P37114 & trans-cinnamate 4-monooxygenase & trans-4-coumarate biosynthesis, phenylpropanoid metabolism \\
\hline P37115 & trans-cinnamate 4-monooxygenase & trans-4-coumarate biosynthesis, phenylpropanoid metabolism \\
\hline Q6ETN3 & probable 4-coumarate-CoA ligase 3 & phenylpropanoid metabolic process \\
\hline B8RCD3 & trans-anol $O$-methyltransferase 1 & phenylpropanoid biosynthetic process \\
\hline Q9CAI3 & probable cinnamyl alcohol dehydrogenase 1 & lignin biosynthetic process \\
\hline Q05964 & naringenin,2-oxoglutarate 3-dioxygenase & flavonoid biosynthetic process \\
\hline Q84V83 & leucoanthocyanidin reductase & proanthocyanidin biosynthetic process \\
\hline Q9LRC8 & baicalin-beta- $D$-glucuronidase & flavonoids \\
\hline Q9FK25 & flavone 3'-O-methyltransferase 1 & flavonol biosynthetic, lignin biosynthetic process \\
\hline
\end{tabular}


aspects of plant cell growth and development, including fundamental processes, such as cell division, cell expansion, intracellular organization, and motility, as well as regulators and targets of biotic interactions. ${ }^{46}$

The proteomic study allowed the identification of several proteins involved in important metabolic pathways (Figure 4) and defense responses to biotic and abiotic stresses, which are vital to the growth and development of the plant.

\section{Combined use of histochemical and proteomic studies}

Given the biological importance of quinonemethide triterpenes and sesquiterpene pyridine alkaloids, as well as the restricted accumulation in the roots of $M$. ilicifolia, the combined use of histochemical and proteomic approaches can notably characterize differential metabolite and protein distribution, especially to address possible biological and ecological functions.

In this study, histochemical analysis contributed to the localization of flavonoids in the cortex (Figure 2d). In addition, shotgun proteomic analysis led to the identification of proteins involved in the biosynthesis of flavonoids (EC number and KEGG map, Table S3 and Figure S4, SI section) and strigolactones (Table 1).

Flavonoids are synthesized in the cytosol, accumulate in vacuoles and can be transported for exudation into the rhizosphere. In the rhizosphere, flavonoids play important roles in biological communications with rhizobia, arbuscular mycorrhizal fungi, plant growth-promoting rhizobacteria, pathogens, nematodes, and allelopathic interactions between plants. ${ }^{47}$

In addition, strigolactones are also present in exudates and are proposed as essential signal molecules in the establishment of arbuscular mycorrhiza symbiosis. ${ }^{48}$ These symbiotic associations are of considerable ecological importance once they regulate nutrient and carbon cycles and influence soil structure and fertility, as well as stress resistance and tolerance. ${ }^{49}$

According to our results, it is suggested that the flavonoids located in cortical cells act as signaling molecules to establish interactions between the microbial communities of the rhizosphere, microorganisms that inhabit the soil, and other plants.

In addition, histochemical analysis showed a large number of cortical parenchyma cells and secondary xylem cells containing many starch grains (Figures $2 \mathrm{a}-2 \mathrm{~b}$ ). Our proteomic data revealed enzymes involved in the biosynthesis of starch (EC number and KEGG map, Table S3 and Figure S5, SI section), phytohormone auxin, and flavonoids.
Starch is the major energy storage polysaccharide and carbon source in plants. Starch has emerged as a key molecule in mediating responses to abiotic stresses. ${ }^{50}$ In nonphotosynthetic cells, starch is synthesized in amyloplasts of root-cap columella cells and is important for the perception of gravity. ${ }^{51}$ The stimulus response to gravity is mediated by the asymmetric distribution of the phytohormone auxin. There is evidence that flavonoids modulate auxin transport and tropic responses. ${ }^{52}$

The insertion of our data points to the important biological function of starch as a reserve of carbon and energy, in the perception of gravity and responses to abiotic stresses.

Additionally, the histochemical analysis contributed to the localization of the quinonemethide triterpenes in the cells of the phellem, which is characterized by having its cell walls suberized (Figure 2c). The suberized cell walls are primarily composed of suberin associated with waxes, cutin and lignin, forming a protective barrier that plays important biological roles in protecting in response to biotic and abiotic stresses. ${ }^{53,54}$

In this study, proteomic analyses contributed to the identification of enzymes that are involved in the lignin biosynthetic process (Table 1) and a cytochrome P450dependent fatty acid oxidase, CYP86A2, involved in the synthesis of cutin. These enzymes should be directly involved in the biosynthetic processes of the monomers that constitute the suberin aromatic and aliphatic domains. ${ }^{55}$

Additionally, enzymes that are essential in the biosynthesis of triterpenes and that are directly involved in the biosynthesis and cyclization of 2,3-oxidosqualeno, a precursor of the quinonemethide triterpenes, were also identified (Table 1).

Some quinonemethide triterpenes are known for their cytotoxicity and antimicrobial activity, and the presence of these compounds has been reported in several Maytenus species (Celastraceae). ${ }^{16,17,56}$ Some works ${ }^{3,6}$ have shown that to avoid the autotoxicity of some lipophilic compounds, plants usually sequester and store these compounds in the cuticle in ducts or dead resin cells, which are lined with an impermeable solid barrier.

Thus, we speculate that the function of suberin may be the storage of the quinonemethide triterpenes. The location of the quinonemethide triterpenes in the outer layers of the periderm (phellem) associated with their antimicrobial activity ${ }^{16,17}$ makes it possible to speculate that the quinonemethide triterpenes play an important role in the first line of defense against pathogenic microorganisms that inhabit the soil.

The histochemical analysis also contributed to the localization of the sesquiterpene pyridine alkaloids in 


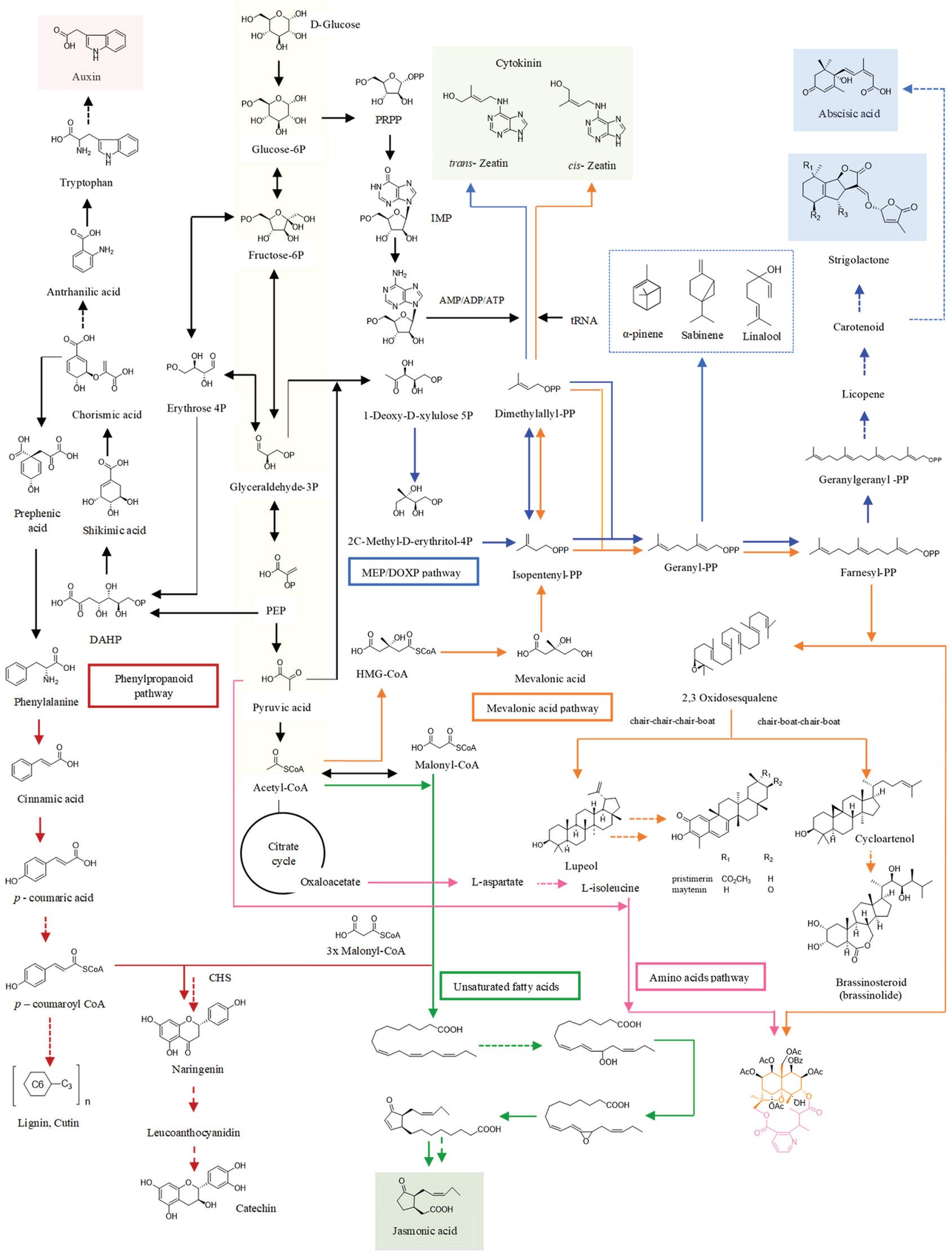

Figure 4. Summary of metabolic pathways predicted from proteomic analysis in roots of M. ilicifolia. Blue line: methylerythritol phosphate (MEP), orange line: mevalonate (MVA), rose line: aminoacids, red line: phenylpropanoid, green line: unsaturated fatty acids. 
the cells of the phellem, the cortex, and the secondary xylem (fibers) (Figures 2e-2f). Alkaloid biosynthesis and accumulation are associated with a diversity of cell types; for example, putrescine $N$-methyltransferase (PMT) is the first enzyme committed for the biosynthesis of nicotine and tropane alkaloids. However, the expression of PMT transcripts is confined to the roots of tobacco and localized in young roots, specifically in cortical cells, including the endodermis, and in xylem cells. ${ }^{57}$

Many of the sesquiterpene pyridine alkaloids isolated from the roots of Celastraceae species showed cytotoxic activity. ${ }^{58}$ Generally, alkaloids accumulate and are stored in specific cell types because of their cytotoxicity, and their location is crucial for their effectiveness in plant defense responses. ${ }^{59,60}$ These results are in keeping with the data obtained by a previous report, ${ }^{61,62}$ which showed that alkaloids accumulate with a variety of cell types, suggesting their involvement in plant interaction/or defense with/ against microorganisms that inhabit the soil.

In addition, the shotgun proteomic analysis led to the identification of 3-hydroxy-3-methylglutaryl-coenzyme A reductase (HMG-CoA) and (2E,6E)-farnesyl diphosphate synthase, the main precursors of the dihydro- $\beta$-agarofuran type sesquiterpene (Table 1). The sesquiterpene pyridine alkaloids are characterized from a biosynthetic point of view by a mixed route, with the sesquiterpene unit coming from the mevalonate (MVA) pathway and the alkaloid moiety from glyceraldehyde 3-phosphate and amino acid precursors. ${ }^{63}$

\section{Conclusions}

This study showed the combined use of histochemical and proteomic tools in the roots of M. ilicifolia in natura, allowed a better understanding of the location of the major metabolites and enabled the large-scale acquisition of information on the repertoire of proteins involved in primary and secondary metabolism. Furthermore, our study is the first report of a repertoire of proteins involved in the regulation of secondary metabolism in M. ilicifolia roots.

Finally, these results regarding primary and secondary metabolites analyses may provide a reference for further research investigating the biological and ecological functions of these compounds.

\section{Supplementary Information}

Supplementary information (protein identification data: accession number, peptide sequence, ion score, protein score, biological process, functional category distribution based on biological process, KEGG pathway, EC number, KEGG maps), is available free of charge at http://jbcs.sbq.org.br as PDF file.

\section{Acknowledgments}

This work was supported by the São Paulo Research Foundation (FAPESP), grant numbers: CIBFar-2013/07600-3, INCT-FAPESP-2014/50926-0. This study was also financed by INCT-CNPq-2014/465637-0. V. A. F. F. M. S. thanks FAPESP and CNPq for the provision of fellowships (2011/0154-9 and 150201/2015-0, respectively). M. F., S. P. T., and M. S. P. thank CNPq for their fellowship. V. A. F. F. M. S. is also grateful to the Pro-Rectory for research of UNESP (PROPe) for financial support.

\section{References}

1. Santner, A.; Calderon-Villalobos, L. I. A.; Estelle, M.; Nat. Chem. Biol. 2009, 5, 301.

2. Croteau, R.; Kutchan, T. M.; Lewis, N. G.; In Biochemistry \& Molecular Biology of Plants; Buchanan, B. B.; Gruissem, W.; Jones, R. L., eds.; American Society of Plant Physiologists: Rockville, 2000, ch. 24.

3. Wink, M.; Biochemistry of Plant Secondary Metabolism, Annual Plant Reviews, $2^{\text {nd }}$ ed.; Wiley-Blackwell: Oxford, 2010, ch. 1.

4. Cragg, G. M.; Newman, D. J.; Biochim. Biophys. Acta 2013, $1830,3670$.

5. Pan, S.-Y.; Zhou, S.-F.; Gao, S.-H.; Yu, Z.-L.; Zhang, S.-F.; Tang, M.-K.; Sun, J.-N.; Ma, D.-L.; Han, Y.-F.; Fong, W.-F.; Ko, K.-M.; J. Evidence-Based Complementary Altern. Med. 2013, 2013, 627375.

6. Kutchan, T. M.; Curr. Opin. Plant Biol. 2005, 8, 292.

7. di Stasi, L. C. In Conservação e Uso Sustentável de Plantas Medicinais e Aromáticas: Maytenus spp., Espinheira-Santa; Reis, M. S.; Silva, S. R., eds.; IBAMA: Brasília, 2004, p. 67.

8. Brüning, R.; Wagner, H.; Phytochemistry 1978, 17, 1821.

9. Santos, V. A. F. F. M.; Santos, D. P.; Castro-Gamboa, I.; Zanoni, M. V. B.; Furlan, M.; Molecules 2010, 15, 6956.

10. Carvalho, P. R. F.; Silva, D. H. S.; Bolzani, V. S.; Furlan, M.; Chem. Biodiversity 2005, 2, 367.

11. Gullo, F. P.; Sardi, J. C. O.; Santos, V. A. F. F. M.; Sangalli-Leite, F.; Pitangui, N. S.; Rossi, S. A.; de Paula Silva, A. C. A.; Soares, L. A.; Silva, J. F.; Oliveira, H. C.; Furlan, M.; Silva, D. H. S.; Bolzani, V. S.; Mendes-Giannini, M. J. S.; Fusco-Almeida, A. M.; J. Evidence-Based Complementary Altern. Med. 2012, 3, 340787.

12. Costa, P. M.; Ferreira, P. M. P.; Bolzani, V. S.; Furlan, M.; Santos, V. A. F. F. M.; Corsino, J.; Moraes, M. O.; Costa-Lotufo, L. V.; Montenegro, R. C.; Pessoa, C.; Toxicol. In Vitro 2008, 22, 854.

13. Santos, V. A. F. F. M.; Leite, K. M.; Siqueira, M. C.; Regasini, L. O.; Martinez, I.; Nogueira, C. T.; Galuppo, M. K.; Stolf, B. 
S.; Pereira, A. M. S.; Cicarelli, R. M. B.; Furlan, M.; Graminha, M. A. S.; Molecules 2013, 18, 1053.

14. Peng, B.; Xu, L.; Cao, F.; Wei, T.; Yang, C.; Uzan, G.; Zhang, D.; Mol. Cancer 2010, 9, 79.

15. Sung, B.; Park, B.; Yadav, V. R.; Aggarwal, B. B.; J. Biol. Chem. 2010, 285, 11498.

16. Sotanaphun, U.; Lipipun, V.; Suttisri, R.; Bavovada, R.; Planta Med. 1999, 65, 450.

17. Moujir, L.; Gutierreznavarro, A. M.; Gonzalez, A. G.; Ravelo, A. G.; Luis, J. G.; Biochem. Syst. Ecol. 1990, 18, 25.

18. Jardim, A. C. G.; Igloi, Z.; Shimizu, J. F.; Santos, V. A. F. F. M.; Felippe, L. G.; Mazzeu, B. F.; Amako, Y.; Furlan, M.; Harris, M.; Rahal, P.; Antiviral Res. 2015, 115, 39.

19. Santos, V. A. F. F. M.; Regasini, L. O.; Nogueira, C. R.; Martinez, I.; Bolzani, V. S.; Graminha, M. A. S.; Cicarelli, R. M. B.; Furlan, M.; J. Nat. Prod. 2012, 75, 991.

20. Johansen, D. A.; Plant Microtechnique; McGraw-Hill Book Company: New York, London, 1940.

21. Svendsen, A. B.; Verpoorte, R.; Cromatography of Alkaloids; Elsevier Scientific Publishing Company: Amsterdam, New York, 1983.

22. Hurkman, W. J.; Tanaka, C. K.; Plant Physiol. 1986, 8, 802.

23. Stoscheck, C. M. In Methods in Enzymology; Deutscher, M. P., ed.; Academic Press: New York, San Diego, 1990, ch. 6.

24. https://www.ncbi.nlm.nih.gov/protein/?term=Viridiplantae, accessed in August 2020.

25. https://www.uniprot.org/uniprot/?query=viridiplantae $\&$ fil=rev iewed\%3Ayes\&sort=score, accessed in August 2020.

26. http://www.matrixscience.com/, accessed in August 2020.

27. Huntley, R. P.; Sawford, T.; Mutowo-Meullenet, P.; Shypitsyna, A.; Bonilla, C.; Martin, M. J.; O’Donovan, C.; Nucleic Acids Res. 2015, 43 (Database issue), D1057.

28. Conesa, A.; Götz, S.; Int. J. Plant Genomics 2008, 2008, 619832.

29. Blast $2 G O$ bioinformatics software, version 4.1, available at http://www.blast2go.com, accessed in August 2020.

30. Kanehisa, M.; Goto, S.; Nucleic Acids Res. 2000, $28,27$.

31. Lange, B. M.; Fischedick, J. T.; Lange, M. F.; Srividya, N.; Šamec, D.; Poirier, B. C.; Plant Physiol. 2017, 173, 456.

32. Corsino, J.; Carvalho, P. R. F.; Kato, M. J.; Oliveira, O. M. F.; Araújo, A. R.; Bolzani, V. S.; Pereira, A. M. S.; França, S. C.; Furlan, M.; Phytochemistry 2000, 55, 741.

33. Overvoorde, P.; Fukaki, H.; Beeckman, T.; Cold Spring Harbor Perspect. Biol. 2010, 6, a001537.

34. León, I. P.; Hamberg, M.; Castresana, C.; Front Plant Sci. 2015, $6,483$.

35. Saini, S.; Sharma, I.; Kaur, N.; Pati, P.; Plant Cell Rep. 2013, 32, 741.

36. Haffani, Y.Z.; Silva, N. F.; Goring, D. R.; Can. J. Bot. 2004, 82, 1.

37. Mhamdi, A.; van Breusegem, F.; Development 2018, 145, dev164376.

38. Vogt, T.; Mol. Plant 2010, 3, 2.
39. Pinto-Zevallos, D. M.; Martins, C. B. C.; Pellegrino, A. C.; Zarbin, P. H. G.; Quim. Nova 2013, 36, 1395.

40. Souza-Moreira, T. M.; Alves, T. B.; Pinheiro, K. A.; Felippe, L. G.; de Lima, G. M. A.; Watanabe, T. F.; Barbosa, C. C.; Santos, V. A. F. F. M.; Lopes, N. P.; Valentini, S. R.; Guido, R. V. C.; Furlan, M.; Zanelli, C. F.; Sci. Rep. 2016, 6, 36858.

41. Alves, T. B.; Souza-Moreira, T. M.; Valentini, S. R.; Zanelli, C. F.; Furlan, M.; Molecules 2018, 23, 700.

42. Bicalho, K. U.; Santoni, M. M.; Arendt, P.; Zanelli, C. F.; Furlan, M.; Goossens, A.; Pollier, J.; Plant Cell Physiol. 2019, 60, 2510.

43. Choe, S.; Physiol. Plant. 2006, 126, 539.

44. Barratt, D. H.; Derbyshire, P.; Findlay, K.; Pike, M.; Wellner, N.; Lunn, J.; Feil, R.; Simpson, C.; Maule, A. J.; Smith, A. M.; Proc. Natl. Acad. Sci. USA 2009, 106, 13124.

45. Marowa, P.; Ding, A.; Kong, Y.; Plant Cell Rep. 2016, 35, 949. 46. Takemoto, D.; Hardham, A. R.; Plant Physiol. 2004, 136, 3864. 47. Sugiyama, A.; Yazaki, K.; Plant Biotechnol. 2014, 31, 431.

48. Steinkellner,S.;Lendzemo, V.; Langer,I.; Schweiger,P.; Khaosaad, T.; Toussaint, J.-P.; Vierheilig, H.; Molecules 2007, 12, 1290.

49. Chen, M.; Arato, M.; Borghi, L.; Nouri, E.; Reinhardt, D.; Front. Plant Sci. 2018, 9, 1270.

50. Thalmann, M.; Santelia, D.; New Phytol. 2017, 214, 943.

51. Morita, M. T.; Annu. Rev. Plant Biol. 2010, 61, 705.

52. Santelia, D.; Henrichs, S.; Vincenzetti, V.; Sauer, M.; Bigler, L.; Klein, M.; Bailly, A.; Lee, Y.; Friml, J.; Geisler, M.; Martinoia, E.; J. Biol. Chem. 2008, 283, 31218.

53. Pollard, M.; Beisson, F.; Li, Y.; Ohlrogge, J. B.; Trends Plant Sci. 2008, 13, 236.

54. Liu, Q.; Luo, L.; Zheng, L.; Int. J. Mol. Sci. 2018, 19, 335.

55. Graça, J.; Front. Chem. 2015, 3, 62.

56. Oramas-Royo, S. M.; Chávez, H.; Martín-Rodíguez, P.; Fernández-Pérez, L.; Ravelo, A. G.; Estévez-Braun, A.; J. Nat. Prod. 2010, 73, 2029.

57. Shoji, T.; Yamada, Y.; Hashimoto, T.; Plant Cell Physiol. 2000, 41,831 .

58. Kuo, Y.; King, M.; Chen, G.; Chen, H.; Chen, C.; Chen, L.; Lee, K.; J. Nat. Prod. 1994, 57, 263.

59. Ziegler, J.; Facchini, P. J.; Annu. Rev. Plant Biol. 2008, 59, 735.

60. Matsuura, H. N.; Fett-Neto, A. G. In Plant Toxins; Gopalakrishnakone, P.; Carlini, C.; Ligabue-Braun, R., eds.; Springer: Dordrecht, 2015, p. 243.

61. St-Pierre, B.; Vazquez-Flota, F. A.; de Luca, V.; Plant Cell 1999, 11,887 .

62. Bird, D. A.; Franceschi, V. R.; Facchini, P. J.; Plant Cell 2003, $15,2626$.

63. Lião, L. M. In The Alkaloids: Chemistry and Biology; Cordell, G. A., ed.; Elsevier: San Diego, 2003, ch. 5, p. 287.

Submitted: May 8, 2020

Published online: August 25, 2020 